\title{
Synthesis of photocatalytic $\mathrm{TiO}_{2}$ thin films via the high-pressure crystallization process at low temperatures
}

\author{
Chung-Hsin Lu*, Wei-Hong Wu, R.B. Kale \\ Department of Chemical Engineering, National Taiwan University, Taipei, Taiwan, ROC
}

Received 2 November 2006; received in revised form 21 December 2006; accepted 28 December 2006

Available online 4 January 2007

\begin{abstract}
$\mathrm{TiO}_{2}$ thin films with a monophasic anatase structure were synthesized via a high-pressure crystallization (HPC) process which successfully lowered the crystallization temperature of $\mathrm{TiO}_{2}$ films from 350 to $150{ }^{\circ} \mathrm{C}$. The thermal budget and energy consumption during the crystallization process were markedly reduced and dense films without cracks were obtained. During the HPC process, crystallization took place throughout the films and $\mathrm{TiO}_{2}$ films with uniform crystallinity were obtained. The HPC process also led to an enhancement in the wettability of TiO ${ }_{2}$ thin films. The hydrophilicity of the films increased with heating temperatures via high-pressure annealing. In comparison with the conventional annealing, the HPC process not only produced $\mathrm{TiO}_{2}$ films with superior photo-induced super-hydrophilicity, but also led to higher photocatalytic activity of the films. The HPC process was confirmed to provide a new route for synthesizing well-crystallized anatase $\mathrm{TiO}_{2}$ thin films with high photocatalytic activity and good wettability at low temperatures.
\end{abstract}

(C) 2007 Elsevier B.V. All rights reserved.

Keywords: Thin films; Titanium dioxide; High-pressure crystallization; Photocatalytic activity

\section{Introduction}

Titanium dioxide $\left(\mathrm{TiO}_{2}\right)$, a promising compound in terms of technological applications, has been extensively studied because of its excellent chemical stability, mechanical hardness, high oxidation affinity and optical transmittance with high refractive index [1]. Recently, nanocrystalline $\mathrm{TiO}_{2}$ has been the focus of investigation for been utilized as a non-toxic, low cost material in various applications including dye sensitized solar cells [2], gate oxides in transistors (MOS-FETs) [3,4], thin film capacitors [5], gas sensors [6], photocatalysis and pigments [7-14]. The amphiphilic $\mathrm{TiO}_{2}$ surface induced by UV light is expected to be applicable to windshields and mirrors for vehicles [15].

Most semiconductors investigated as photocatalysts in the present days belong to n-type semiconductors, including $\mathrm{TiO}_{2}$, $\mathrm{ZnO}, \mathrm{CdSe}, \mathrm{WO}_{3}, \mathrm{Fe}_{2} \mathrm{O}_{3}, \mathrm{PbS}, \mathrm{SnO}_{2}, \mathrm{In}_{2} \mathrm{O}_{3}, \mathrm{ZnS}, \mathrm{SrTiO}_{3}$, $\mathrm{SiO}_{2}$, etc. [16]. These semiconductors have certain degree of photocatalytic activities in breaking down organic compounds. But most of them are chemically or photochemically corrosive

\footnotetext{
* Corresponding author. Tel.: +886 2223651428.

E-mail address: chlu@ntu.edu.tw (C.-H. Lu).
}

indicating that they cannot be applied to water purification. $\mathrm{TiO}_{2}$ thin films as a photocatalyst (mostly in anatase phase) has the advantages of acid resistance, base resistance, good chemical and photochemical stability, non-toxicity, low cost, and high photocatalytic activity. These advantages have attracted intensive research to be focused on $\mathrm{TiO}_{2}$.

$\mathrm{TiO}_{2}$ thin films can be prepared using various chemical methods such as chemical bath deposition, electrodeposition, ionic layer adsorption and reaction, and sol-gel process [15,17-20]. In these chemical methods, the as-synthesized $\mathrm{TiO}_{2}$ films are amorphous and high-temperature heating at or above $350{ }^{\circ} \mathrm{C}$ is required to transform the amorphous phases into crystalline phases. Recently, a novel high-pressure crystallization (HPC) process developed by our group [21] has been used to successfully crystallize ceramic thin films at a temperature considerably lower than that required in the commonly adopted atmosphericpressure annealing process $[22,23]$.

In the present study, the HPC process was successfully utilized to lower the crystallization temperature of $\mathrm{TiO}_{2}$ thin films. Various aspects such as crystal quality, crystallite size, crystallization degree, super-hydrophilicity, microstructure, and photocatalytic activity of $\mathrm{TiO}_{2}$ thin films were investigated as a function of annealing temperature in the HPC process, and the 
obtained results were compared with those of $\mathrm{TiO}_{2}$ thin films annealed under atmospheric pressure.

\section{Experimental}

Metalorganic deposition method (MOD) and spin-coating method were adopted to prepare titanium dioxide precursor films in this study. The metalorganic solution serving as a source consisted of titanium tetraisopropoxide as the starting material. The substrates used in this experiment were Si wafers. The metalorganic solution was spin-coated onto the cleaned Si substrates via two-step spinning. Excess solutions of the precursors were removed at a spinning rate of $3000 \mathrm{rpm}$ in the first step. In the second step, most of the solvents were evaporated at a spinning rate of $4000 \mathrm{rpm}$ and the resultant films became more uniform. The obtained films were further baked on a hot plate at $150{ }^{\circ} \mathrm{C}$ for $10 \mathrm{~min}$ to remove any residual organic solvents. The dried thin films were pyrolyzed at $325^{\circ} \mathrm{C}$ for $30 \mathrm{~min}$ to evaporate the residual organics. The above mentioned spin coating, baking, and pyrolysis procedures were carried out repeatedly for three times to obtain the desired film thickness of around $0.4 \mu \mathrm{m}$.

Two different annealing processes were adopted to crystallize the as-pyrolyzed films. The first one was to heat the as-pyrolyzed films under atmospheric pressure $\left(1.01 \times 10^{5} \mathrm{~Pa}\right)$ in an electric furnace in the temperature range of $350-600{ }^{\circ} \mathrm{C}$ for $2 \mathrm{~h}$. The second one was to anneal the as-pyrolyzed films via the highpressure crystallization process carried out in a closed stainless bomb under high pressure $\left(4.34 \times 10^{5}\right.$ to $\left.4.05 \times 10^{6} \mathrm{~Pa}\right)$ in the temperature range of $150-250^{\circ} \mathrm{C}$ for $2 \mathrm{~h}$. The bomb was filled with deionized water to create high-pressure saturated steam at elevated temperatures over $100^{\circ} \mathrm{C}$. During the HPC process, the as-pyrolyzed films were placed above the water surface to prevent direct contact with water.

To examine the crystal structures of $\mathrm{TiO}_{2}$ thin films, X-ray Diffraction (XRD) was utilized to determine the crystallization degree of the thin films. The surface morphologies of the thin films were observed by scanning electron microscopy (SEM). The crystal structures of the annealed films in different depths were analyzed via grazing incident X-ray diffraction (GIXD). The contact angles of the annealed films were measured via a camera and a computer program. The photocatalytic characteristics of the annealed films were investigated based on the decomposition of methylene blue. Ten milliliters of $30 \mu \mathrm{M}$ methylene blue solution was used in this study. The annealed films were immersed in the methylene blue solutions and illuminated under UV light of $1.2 \mathrm{~mW} / \mathrm{cm}^{2}$ in intensity. The decomposed methylene blue solutions were analyzed via an UV-vis spectrometer (Hitachi U-2001).

\section{Results and discussion}

\subsection{Influence of temperature and pressure on the crystallization of $\mathrm{TiO}_{2}$ thin films}

The as-pyrolyzed $\mathrm{TiO}_{2}$ thin films were annealed under atmospheric pressure at various temperatures. Fig. 1 illustrates the XRD patterns of $\mathrm{TiO}_{2}$ thin films annealed under atmospheric

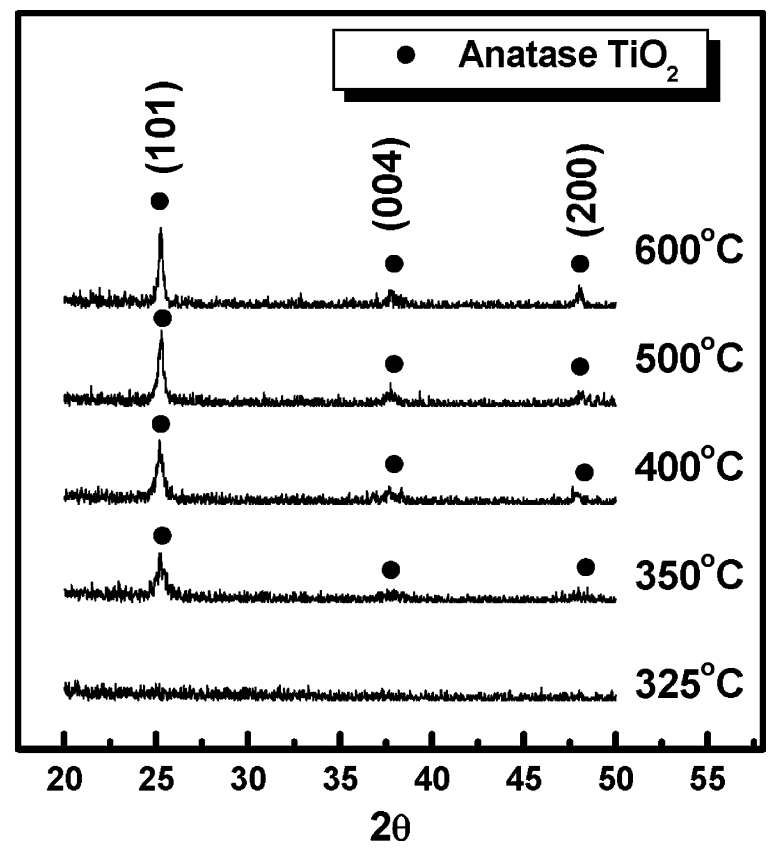

Fig. 1. XRD patterns of $\mathrm{TiO}_{2}$ thin films annealed at different temperatures under atmospheric pressure.

pressure at different temperatures in the range of $325-600{ }^{\circ} \mathrm{C}$ for $2 \mathrm{~h}$. With $325^{\circ} \mathrm{C}$ annealing, no diffraction peaks were detected indicating that the film remained amorphous. When the film was annealed at $350{ }^{\circ} \mathrm{C}$, monophasic anatase-type $\mathrm{TiO}_{2}$ film was formed as indicated in the corresponding XRD pattern in which all diffraction peaks are consistent with the data listed for anatase $\mathrm{TiO}_{2}$ in ICDD file No.: 84-1286. With a further increase in the annealing temperatures, the diffraction peaks became sharpened and their full widths at half maximum (FWHM) became narrower, revealing that the crystallinity of the annealed films were enhanced with high-temperature annealing. As the annealing temperature reached $600^{\circ} \mathrm{C}$, well-crystallized anatase phase of $\mathrm{TiO}_{2}$ was obtained.

In order to lower the crystallization temperature of $\mathrm{TiO}_{2}$ thin films, the high-pressure crystallization process was performed. The XRD patterns of $\mathrm{TiO}_{2}$ thin films annealed via the HPC process are illustrated in Fig. 2. When $\mathrm{TiO}_{2}$ film was annealed at $125^{\circ} \mathrm{C}$ under $2.26 \times 10^{5} \mathrm{~Pa}$ for $2 \mathrm{~h}$, no change in crystallization was observed and the film remained amorphous. When the annealing temperature was slightly raised to $150{ }^{\circ} \mathrm{C}$ with a pressure of $4.34 \times 10^{5} \mathrm{~Pa}$, the XRD peaks corresponding to the anatase phase of $\mathrm{TiO}_{2}$ appeared suggesting the formation of crystallized $\mathrm{TiO}_{2}$ films. It is therefore demonstrated that $\mathrm{TiO}_{2}$ thin films with a monophasic anatase phase can be obtained at a temperature as low as $150{ }^{\circ} \mathrm{C}$. The result also shows that the crystallization temperature of anatase phase of $\mathrm{TiO}_{2}$ thin film was significantly lowered as compared to the conventional atmospheric pressure annealing. Once the as-pyrolyzed films were annealed at $250{ }^{\circ} \mathrm{C}$ under $4.05 \times 10^{6} \mathrm{~Pa}$, the crystallinity of $\mathrm{TiO}_{2}$ was further enhanced.

The crystallite sizes of $\mathrm{TiO}_{2}$ thin films were calculated by using Scherrer's formula. The relations between the annealing temperature and crystallite size are shown in Fig. 3. At the 


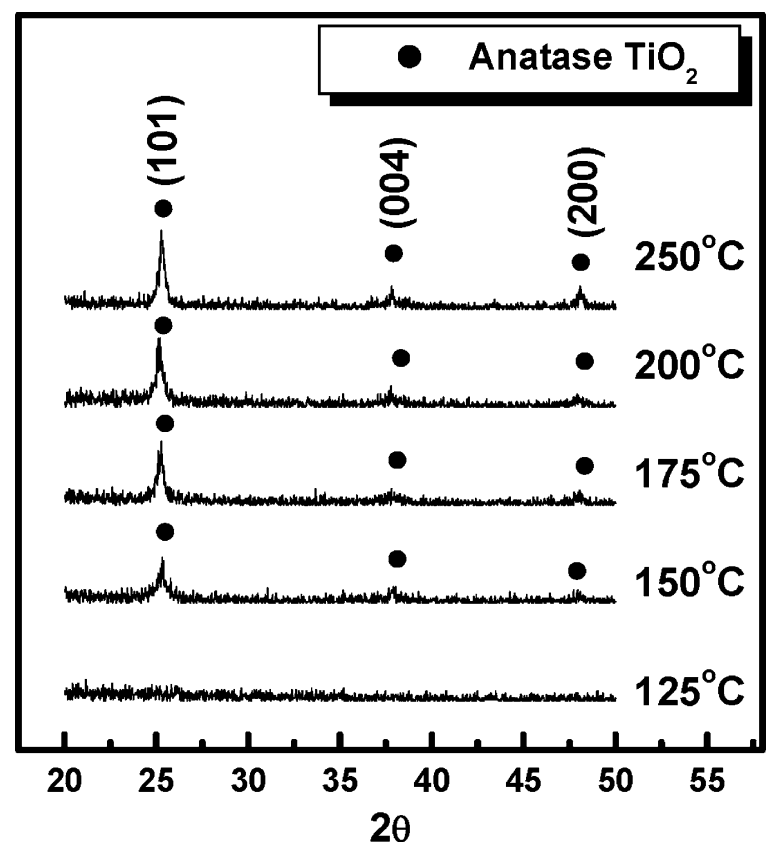

Fig. 2. XRD patterns of $\mathrm{TiO}_{2}$ thin films annealed at different temperatures via HPC process.

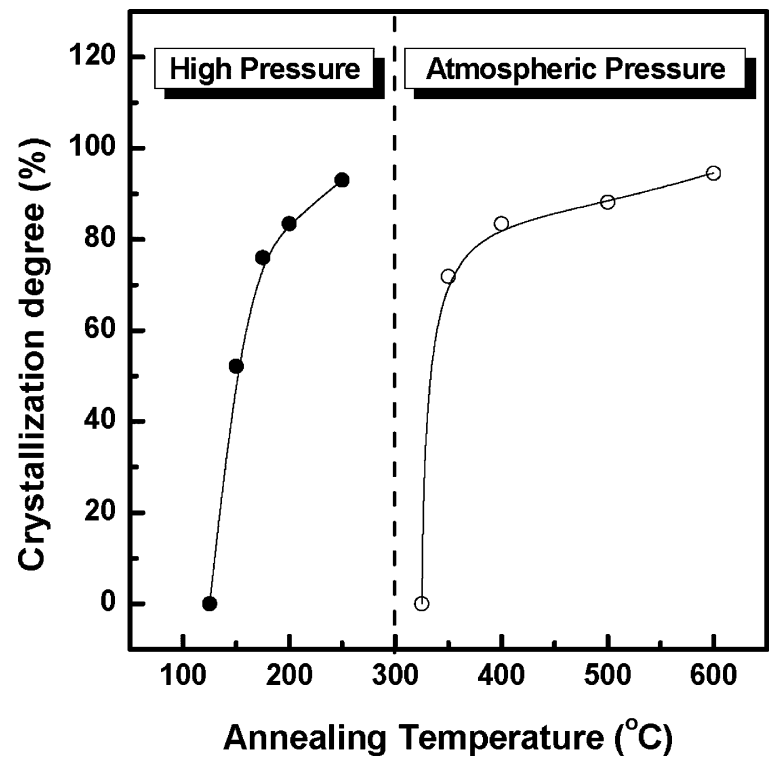

Fig. 3. Relations between crystallite size and annealing temperature for $\mathrm{TiO}_{2}$ thin films annealed under atmospheric and high pressures.

beginning of the crystallization in the HPC process conducted at $150{ }^{\circ} \mathrm{C}$ under $4.34 \times 10^{5} \mathrm{~Pa}$, the average crystallite size of $\mathrm{TiO}_{2}$ thin film was $17 \mathrm{~nm}$. After the as-pyrolyzed film was annealed at $250{ }^{\circ} \mathrm{C}$ under $4.05 \times 10^{6} \mathrm{~Pa}$, the average crystallite size of $\mathrm{TiO}_{2}$ thin film was increased to $23 \mathrm{~nm}$. On the other hand, while the annealing temperature was elevated from 350 to $600{ }^{\circ} \mathrm{C}$ under atmospheric pressure, the average crystallite size of $\mathrm{TiO}_{2}$ thin films was enlarged from 15 to $30 \mathrm{~nm}$.

For the samples with a crystallization degree over $90 \%$, the average crystallite size of $\mathrm{TiO}_{2}$ thin films prepared via the HPC process is smaller than that of the films prepared via the conventional annealing method owing to the low-temperature synthesis.
Hence the HPC process is useful for obtaining nano-crystals with reduced dimensionality at considerably low temperatures, and is thereby especially practicable in the fields of nanoscience and nanotechnology.

\subsection{Microstructures and crystallization of $\mathrm{TiO}_{2}$ thin films}

Fig. 4 shows the surface morphologies of $\mathrm{TiO}_{2}$ thin films annealed under atmospheric and high pressures. The film annealed at $325^{\circ} \mathrm{C}$ under atmospheric pressure exhibited smooth surface with no distinguishable features (Fig. 4(a)). Once the temperature was increased to $350^{\circ} \mathrm{C}$, small nanoparticles were formed on the film, indicating an improvement in the grain growth of $\mathrm{TiO}_{2}$ film (Fig. 4(b)). As for the film annealed at $150{ }^{\circ} \mathrm{C}$ under $4.34 \times 10^{5} \mathrm{~Pa}$, clear features on the film surface were observed (Fig. 4(c)). At the beginning of crystallization process, small nanoparticles were formed and uniformly distributed on the surface. As shown in Fig. 4(d), after annealing at $250{ }^{\circ} \mathrm{C}$ under $4.05 \times 10^{6} \mathrm{~Pa}$, dense $\mathrm{TiO}_{2}$ films without cracks were successfully obtained.

For analyzing the crystallization degree in different depths of $\mathrm{TiO}_{2}$ thin films, grazing incident $\mathrm{X}$-ray diffraction was utilized. The GIXD patterns of the thin films annealed at $350^{\circ} \mathrm{C}$ under atmospheric pressure are illustrated in Fig. 5. $\mathrm{TiO}_{2}$ is a material with high refractive index $(n=2.54)$, and its X-ray penetration depth can be calculated from the following equation [24]:

$D(\omega)=\frac{\sin (\omega)}{\mu}$

where $\omega$ is the incident angle of the X-ray beam and $\mu$ is the linear absorption coefficient. The linear absorption coefficient of $\mathrm{TiO}_{2}$ was calculated to be 0.049 [25]. From the equation listed above, the penetration depths of X-ray into the thin films get deeper with increasing the incident angle of the X-ray beam. As shown in Fig. 5, no diffraction peaks were observed when $\omega$ is $0.1^{\circ}$, indicating that the surface layer of the films remained amorphous. When the incident angle was increased, the diffraction intensity of the films was also increased. This indicates that the crystallization degree of $\mathrm{TiO}_{2}$ thin films was gradually enhanced with depth from the film surface. At $\omega=1.5^{\circ}$, the diffraction pattern showed a maximal intensity. Fig. 6 illustrates the GIXD patterns of $\mathrm{TiO}_{2}$ thin films annealed at $150^{\circ} \mathrm{C}$ in the HPC process. It is found that there is no significant difference in the intensities of the diffraction peaks of $\mathrm{TiO}_{2}$ thin films annealed at $150^{\circ} \mathrm{C}$ with various incident angles, revealing uniform crystallinity throughout the entire films. It is inferred that the crystalline $\mathrm{TiO}_{2}$ anatase phase was obtained throughout the films during high-pressure annealing. The results imply that the crystallization mechanism of the HPC process is different from that of the conventional annealing process $[22,23]$.

\subsection{Super-hydrophilicity and photocatalytic activities of $\mathrm{TiO}_{2}$ thin films}

The enhancement of crystallization by high-pressure annealing is considered to be related to the nucleation process. Annealing under high pressure may lead to a reduction in the 

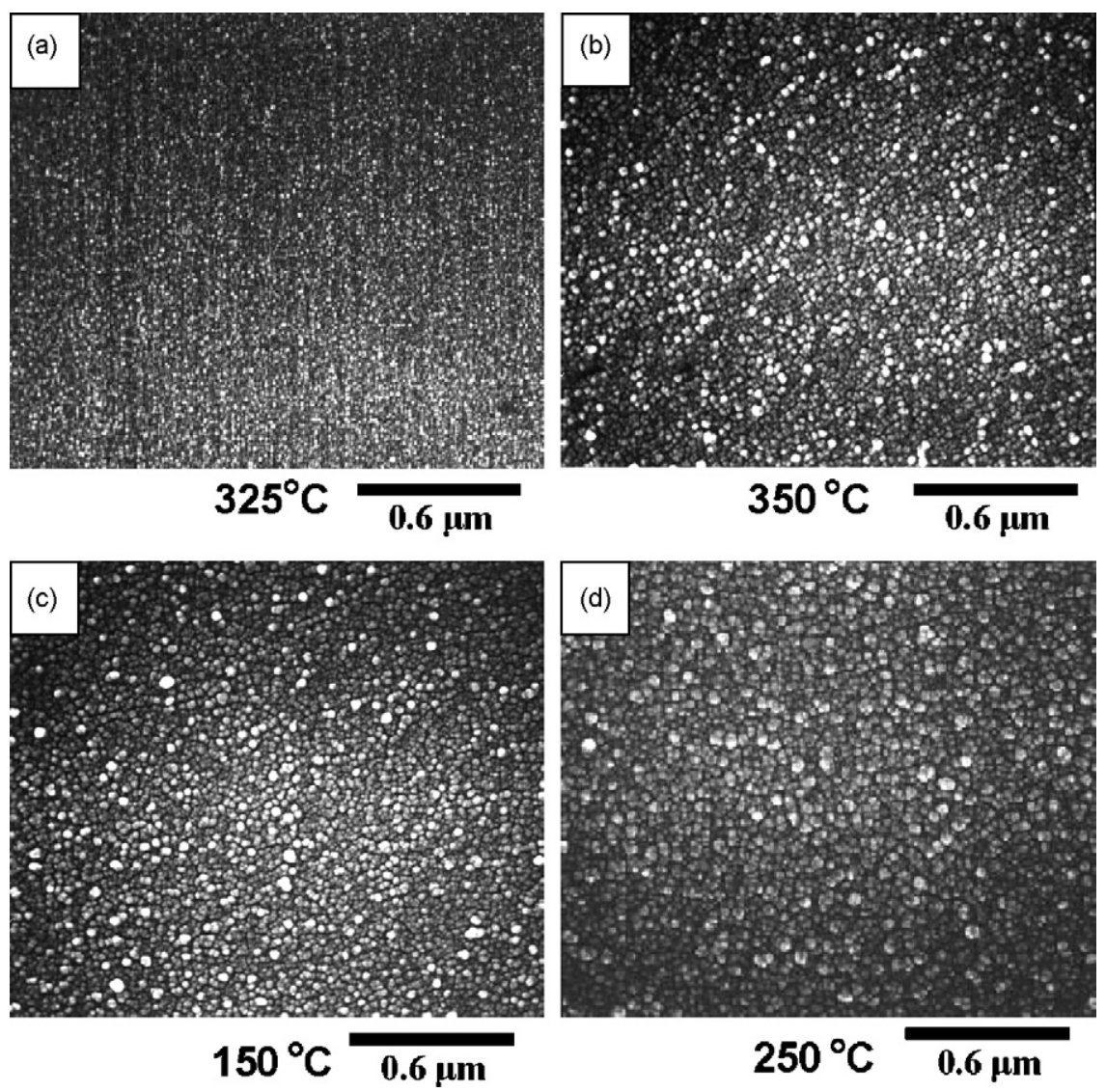

Fig. 4. Scanning electron micrographs of $\mathrm{TiO}_{2}$ thin films prepared at (a) $325^{\circ} \mathrm{C}$ under $1.01 \times 10^{5} \mathrm{~Pa}$, (b) $350{ }^{\circ} \mathrm{C}$ under $1.01 \times 10^{5} \mathrm{~Pa}$, (c) $150{ }^{\circ} \mathrm{C}$ under $4.34 \times 10^{5} \mathrm{~Pa}$, and (d) $250{ }^{\circ} \mathrm{C}$ under $4.05 \times 10^{6} \mathrm{~Pa}$.

critical free energy required for the formation of stable nuclei. As a result, the nucleation process may be facilitated at low temperatures under high pressure [26]. The other possible mechanism is that the high vapor-pressure developed during the

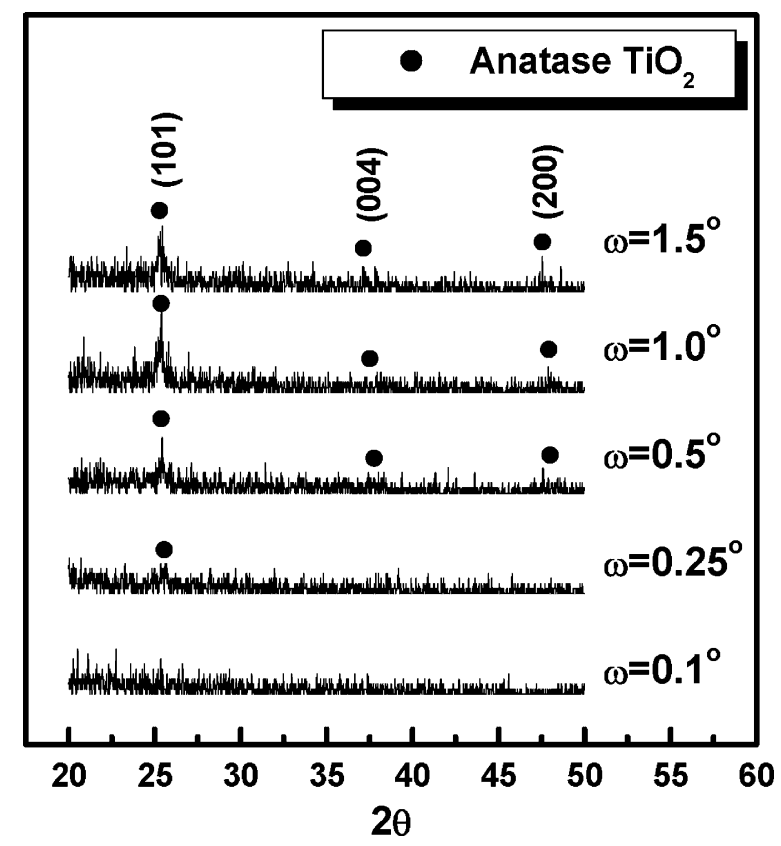

Fig. 5. GIXD patterns of $\mathrm{TiO}_{2}$ thin films annealed at $325^{\circ} \mathrm{C}$ under atmospheric pressure.
HPC process probably forms a water coating on the surfaces of the films, thereby resulting in a dissolution-precipitation process to produce crystallized nuclei at low temperatures [27].

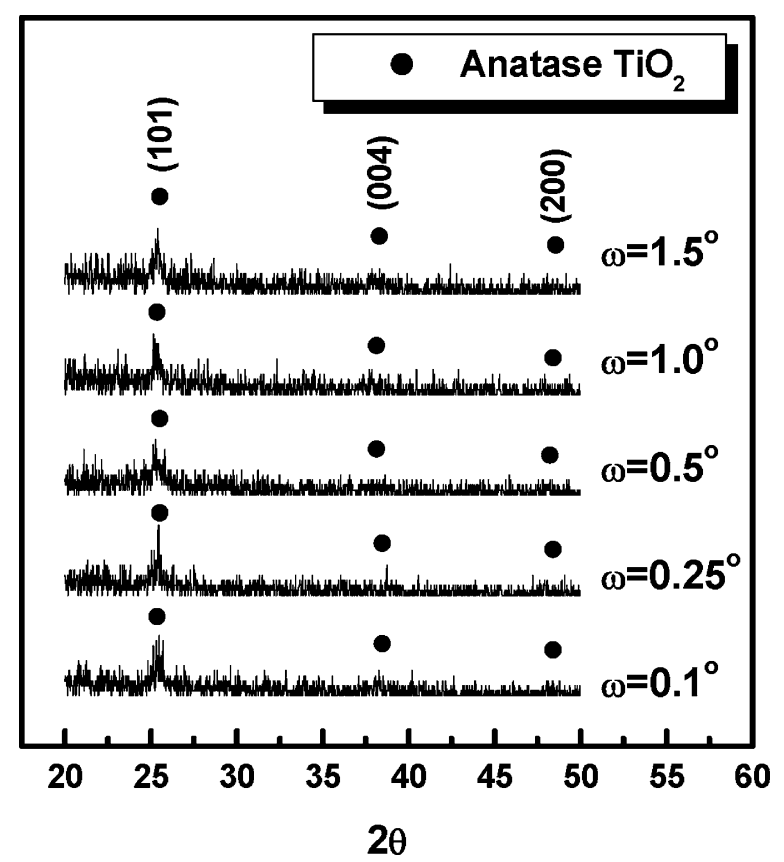

Fig. 6. GIXD patterns of $\mathrm{TiO}_{2}$ thin films annealed at $150^{\circ} \mathrm{C}$ under $4.34 \times 10^{5} \mathrm{~Pa}$. 


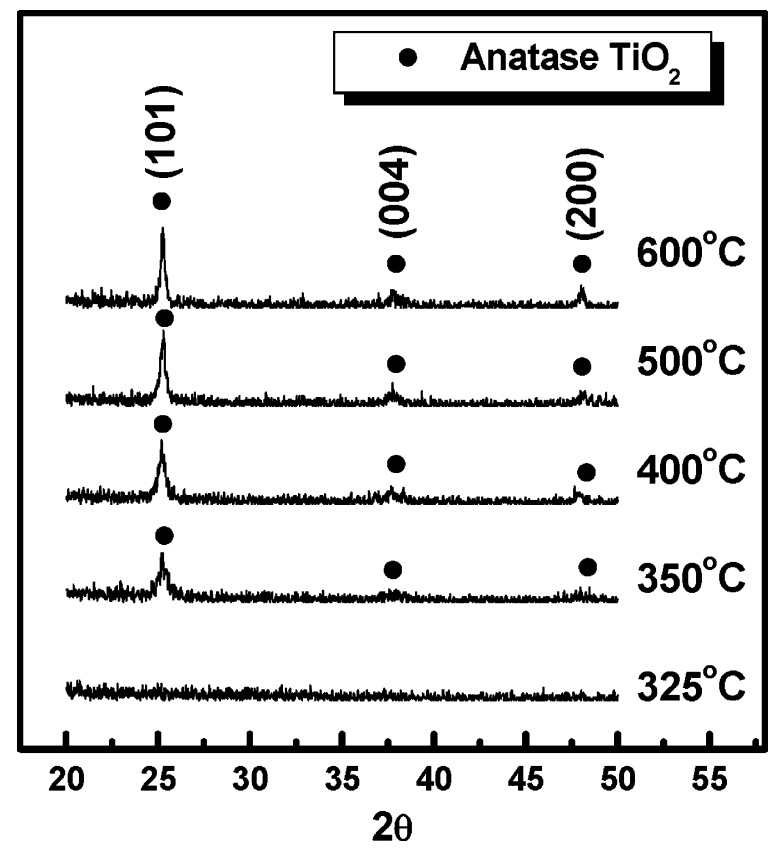

Fig. 7. Relations between contact angle and annealing temperature for $\mathrm{TiO}_{2}$ thin films prepared under atmospheric pressure and via HPC process before UV light illumination.

The effects of annealing temperature on the contact angles of $\mathrm{TiO}_{2}$ thin films prepared under atmospheric and high pressures before UV illumination are shown in Fig. 7. It is found that the contact angles of $\mathrm{TiO}_{2}$ thin films were reduced with annealing temperature. In addition, $\mathrm{TiO}_{2}$ thin films annealed under high pressure had smaller contact angles than those annealed under atmospheric pressure. Hence the surfaces of the thin films annealed via the HPC process were more hydrophilic. The relation between the contact angles of $\mathrm{TiO}_{2}$ thin films and the heating temperature has been investigated by Liu et al. [28] who considered that the change in the contact angles is related to the crystalline state of the films. The crystallization degree of $\mathrm{TiO}_{2}$ thin films annealed at lower temperatures is insufficient and hence the surface of the films is less hydrophilic. As the annealing temperature is elevated, more crystalline anatase $\mathrm{TiO}_{2}$ is formed, resulting in super-hydrophilic nature of the films.

The changes in the contact angles during UV light illumination and dark periods are illustrated in Fig. 8. After UV illumination for $60 \mathrm{~min}$, the contact angle of the amorphous film was larger than $30^{\circ}$, indicating that the surface of the amorphous film was less hydrophilic. As for the films annealed at $150{ }^{\circ} \mathrm{C}$ under $4.34 \times 10^{5} \mathrm{~Pa}$, the contact angle reduced to $0^{\circ}$ after UV light illuminating for $60 \mathrm{~min}$, indicating that superhydrophilicity was achieved. For $\mathrm{TiO}_{2}$ thin films annealed at $600{ }^{\circ} \mathrm{C}$ under atmospheric pressure, the contact angle reduced to $0^{\circ}$ after UV light illumination for $15 \mathrm{~min}$. On the other hand, the illumination time required to reach $0^{\circ}$ of contact angle for the films annealed at $250^{\circ} \mathrm{C}$ under $4.05 \times 10^{6} \mathrm{~Pa}$ was further shortened to $10 \mathrm{~min}$. This result indicates the superhydrophilicity of the films was improved with high-pressure annealing.

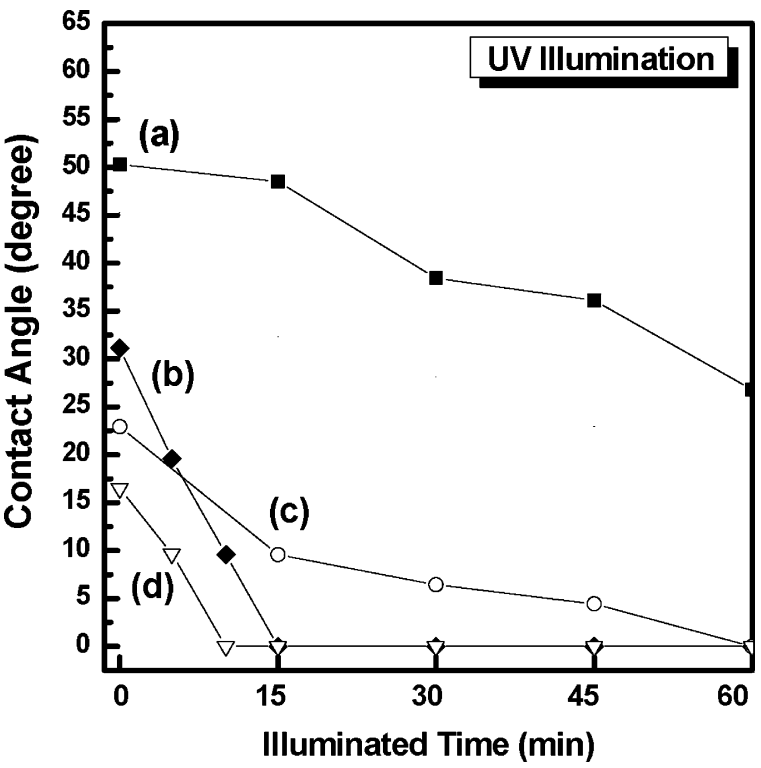

Fig. 8. Plot of changes in contact angle under UV light illumination for (a) amorphous $\mathrm{TiO}_{2}$ films and $\mathrm{TiO}_{2}$ thin films annealed at (b) $600{ }^{\circ} \mathrm{C}$ under $1.01 \times 10^{5} \mathrm{~Pa}$, (c) $150{ }^{\circ} \mathrm{C}$ under $4.34 \times 10^{5} \mathrm{~Pa}$, and (d) $250^{\circ} \mathrm{C}$ under $4.05 \times 10^{6} \mathrm{~Pa}$.

The photocatalytic activities of $\mathrm{TiO}_{2}$ thin films prepared by the two types of annealing processes were analyzed. The absorbance variation of methylene blue solution degraded by $\mathrm{TiO}_{2}$ thin films is illustrated in Fig. 9. The amorphous films did not have obvious photocatalytic activity since the absorbance of methylene blue solution remained nearly unchanged (curve (a)). As for the films annealed at $150^{\circ} \mathrm{C}$ via the HPC process, the absorbance of methylene blue solution changed greatly during the UV illumination process, revealing sufficient photocatalytic activity of these films (curve (b)). For the films annealed at $600{ }^{\circ} \mathrm{C}$ under atmospheric pressure and those annealed at $250{ }^{\circ} \mathrm{C}$

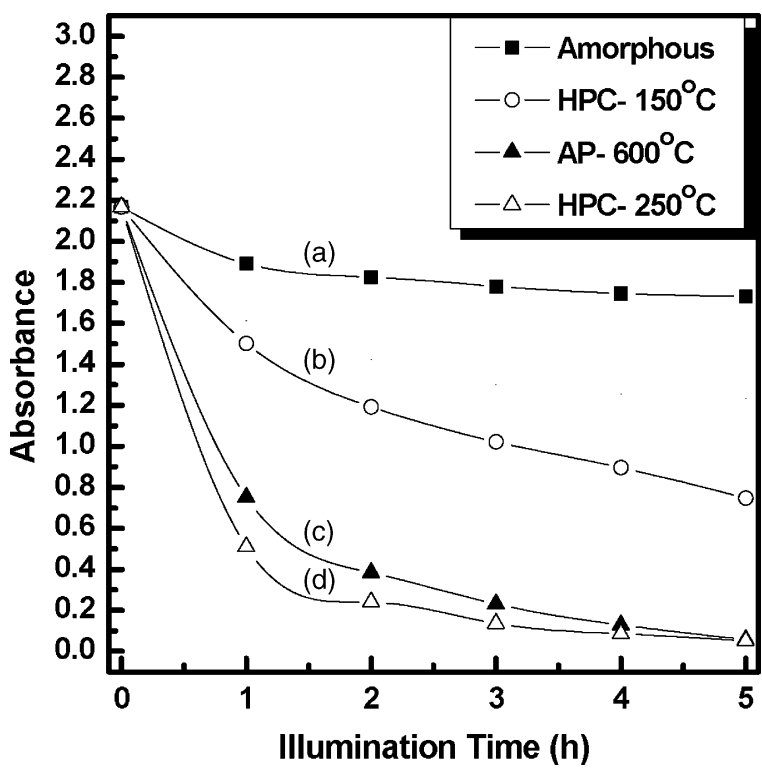

Fig. 9. Degradation of methylene blue for (a) amorphous $\mathrm{TiO}_{2}$ films and $\mathrm{TiO}_{2}$ thin films annealed at (b) $150^{\circ} \mathrm{C}$ under $4.34 \times 10^{5} \mathrm{~Pa}$ (high-pressure crystallization, HPC), (c) $600^{\circ} \mathrm{C}$ under $1.01 \times 10^{5} \mathrm{~Pa}$ (atmospheric pressure, AP), and (d) $250{ }^{\circ} \mathrm{C}$ under $4.05 \times 10^{6} \mathrm{~Pa}$. 
under $4.05 \times 10^{6} \mathrm{~Pa}$, methylene blue was completely degraded after $5 \mathrm{~h}$-illumination (curves (c) and (d)). However, the rate of methylene blue degradation for the films annealed at $250{ }^{\circ} \mathrm{C}$ via the HPC process was faster than that of the films annealed at $600^{\circ} \mathrm{C}$ under atmospheric pressure. It is clearly revealed that $\mathrm{TiO}_{2}$ thin films prepared via the HPC process have superior photocatalytic activity than those derived from the conventional annealing process. During the high-temperature heating process, the silicon species might diffuse into $\mathrm{TiO}_{2}$ films. It has been found that the diffusion of substrate species is detrimental to the photocatalytic activity of $\mathrm{TiO}_{2}$ thin films [29]. The HPC process successfully lowered the required temperature for preparing crystallized $\mathrm{TiO}_{2}$ films and hence minimized the diffusion problems of the substrate species. Therefore, the HPC-derived $\mathrm{TiO}_{2}$ exhibited better photocatalytic activity than that derived by the conventional annealing process.

\section{Conclusions}

Monophasic $\mathrm{TiO}_{2}$ thin films with improved photocatalytic activity were successfully synthesized via the MOD method and subsequent high-pressure crystallization process. The crystallization temperature for amorphous films to become anatase $\mathrm{TiO}_{2}$ films was effectively lowered from 350 to $150^{\circ} \mathrm{C}$ via the HPC annealing process, therefore the thermal budget and energy consumption during the crystallization process were effectively reduced. The crystallization degree of $\mathrm{TiO}_{2}$ thin films was rapidly raised to $93 \%$ with $250{ }^{\circ} \mathrm{C}$ annealing under $4.05 \times 10^{6} \mathrm{~Pa}$. During the HPC process, crystallization took place throughout the films to result in uniform crystallinity of the films. The HPC process also led to an improvement in the wettability of $\mathrm{TiO}_{2}$ thin films. The hydrophilicity of the films increased with heating temperature via high-pressure annealing. In comparison with the conventional annealing, the HPC process not only enhanced the super-hydrophilicity of the derived $\mathrm{TiO}_{2}$ films, but also improved their photocatalytic activities. The developed HPC process can be applied to other inorganic materials for reducing the required energy for crystallization and improving the properties of films.

\section{References}

[1] H.C. Yao, M.C. Chiu, W.T. Wu, F.S. Shieu, J. Electrochem. Soc. 153 (2006) F237.

[2] K. Hou, B. Tian, F. Li, Z. Bian, D. Zhaob, Chunhui Huang, J. Mater. Chem. 15 (2005) 2414.

[3] P.S. Peercy, Nature 406 (2000) 1023.

[4] D.J. Wang, Y. Musuda, W.S. Seo, K. Koumoto, Key Eng. Mater. 214 (2002) 163.

[5] S. Duenas, H. Castan, H. Garcia, E.S. Andres, M. Toledano-Lunque, I. Martil, G. Gonzalez-Diaz, K. Kukil, T. Uustare, J. Aarik, Semicond. Sci. Technol. 20 (2005) 1044.

[6] L.R. Skubal, N.K. Meshkov, M.C. Vogt, J. Photochem. Photobiol. A: Chem. 148 (2002) 103.

[7] M. Anpo, M. Takeuchi, J. Catal. 216 (2003) 503.

[8] C.H. Lu, W.H. Wu, Mater. Sci. Eng. B 113 (2004) 425.

[9] B. Huber, A. Brodyanski, M. Scheib, A. Orendorz, C. Ziegler, H. Gnaser, Thin Solid Films 472 (2005) 114.

[10] J. Nam, T. Amemiya, M. Murabayashi, K. Itoh, J. Phys. Chem. B 108 (2004) 8254.

[11] J. Premkumar, Chem. Mater. 16 (2004) 3980.

[12] K.L. Siefering, G.L. Grifin, J. Electrochem. Soc. 137 (1990) 1206.

[13] L. Miao, S. Tanemura, Y. Konda, M. Iwata, S. Toh, K. Kaneko, Appl. Surf. Sci. 238 (2004) 125.

[14] R. Wang, K. Hasimoto, A. Fujishima, M. Chikuni, E. Kojima, A. Kitamura, M. Shimohigoshi, T. Watanbe, Nature 388 (1997) 431.

[15] C.D. Lokhande, E.H. Lee, K.D. Jung, O.S. Joo, J. Mater. Sci. 39 (2004) 2915.

[16] A. Hagfeld, M. Gratzel, Chem. Rev. 95 (1995) 49.

[17] C.D. Lokhande, S.K. Min, K.D. Jung, O.S. Joo, J. Mater. Sci. 40 (2005) 491.

[18] S.S. Kale, R.S. Mane, H. Chung, M.Y. Yoon, C.D. Lokhande, S.H. Han, Appl. Surf. Sci. 253 (2006) 421.

[19] Z. Yuan, B. Li, J. Zhang, C. Xu, J. Sol-Gel Sci. Technol. 39 (2006) 249.

[20] M.J. Alam, D.C. Cameron, J. Sol-Gel Sci. Technol. 25 (2002) 137.

[21] C.H. Lu, U.S. Patent No. 6143 (2000) 366.

[22] C.H. Lu, Y.C. Chen, J. Mater. Chem. 12 (2002) 1628.

[23] C.H. Lu, W.J. Hwang, Y.C. Sun, Jpn. J. Appl. Phys. 41 (2002) 6674.

[24] C.H. Lu, C.Y. Wen, J. Appl. Phys. 86 (1999) 6335.

[25] B.D. Cullity, Elements of X-ray Diffraction, second ed., Addison Wesley, p. 13.

[26] B. Yao, F.S. Li, X.M. Lin, B.Z. Ding, W.H. Su, Z.Q. Hu, J. Non-Cryst. Solids 217 (1997) 317.

[27] K.W. Seo, J.K. Oh, J. Ceram. Soc. Jpn. 108 (2000) 691.

[28] Q. Liu, X. Wu, B. Wang, Q. Liu, Mater. Res. Bull. 37 (2002) 2255.

[29] Y. Paz, A. Heller, J. Mater. Res. 12 (1997) 2759. 